\title{
Plasma creatinine in the first month of life
}

\author{
H FELDMAN AND J-P GUIGNARD
}

Department of Paediatrics, Centre Hospitalier Universitaire Vaudois, Lausanne, Switzerland

SUMMARY The creatinine-kinetics method of analysis was used to study the changes, during the first month of life, in plasma creatinine levels in 34 newborn infants receiving no treatment with drugs. Plasma creatinine values during the first 5 days of life ranged from 188 to $17 \mu \mathrm{mol} / 1$. After day 5 plasma levels were fairly stable throughout the first month, with a mean value of $35 \pm 2$ (range 12-62) $\mu \mathrm{mol} / 1$. Twenty-two infants receiving treatment with gentamicin-ampicillin-cloxacillin were also studied. Seven of them had raised plasma creatinine concentrations after day 5, well beyond the range of concentrations found for infants receiving no drugs. Plasma creatinine, measured by the kinetic method, appears to provide a useful index of renal function in the neonatal period.

The concentration of creatinine, one of the most simple and most commonly used indices of glomerular filtration rate (GFR) in children and adults, has been reported to be appreciably raised and variable during the first month of life. ${ }^{1-3}$ Although the reason for these high values is unknown, it is clear that they are not entirely the result of immature renal function. ${ }^{1}$ As a consequence, the validity of creatinine as a marker of GFR in the neonate is doubtful. A laboratory test that identifies early reductions in GFR in the neonatal period would lead to earlier and more efficacious treatment of acute renal failure, a condition which is becoming increasingly significant in neonatal intensive care. . $^{4-9}$ In a search for such a test we measured plasma creatinine levels by a reaction kinetic principle (creatinine-kinetics), a technique which seems to minimise the interference of non-creatinine chromogens. ${ }^{1011}$ We here report plasma creatinine concentrations, measured by this method, throughout the first month of life of newborn infants treated in a neonatal unit.

\section{Materials and methods}

Fifty-six infants, all patients at our hospital, were studied during the first month of life. Their gestational ages varied between 30 and 40 weeks. The clinical diagnosis included prematurity, high risk for infection, transient hyperbilirubinaemia, transient mild respiratory distress syndrome, and intrauterine growth retardation. All infants were

This paper was presented at the Fifth International Pediatric Nephrology Symposium, Philadelphia, 6-10 October 1980. stable in room air. Any neonate with oedema, or acid-base or electrolyte disturbance was excluded. Several neonates were studied more than once during their first month of life. Altogether, 126 plasma creatinine concentrations were determined, using $50 \mu \mathrm{l}$ of plasma collected by heel prick, performed only when needed for other reasons. Twenty-two of the 56 infants received, as part of their treatment, gentamicin $(2.5 \mathrm{mg} / \mathrm{kg}$ every 12 hours), ampicillin ( $50 \mathrm{mg} / \mathrm{kg}$ every 6 hours), and cloxacillin $(25 \mathrm{mg} / \mathrm{kg}$ every 6 hours) before the plasma creatinine level was determined. The study was approved by the Committee of Ethics of Lausanne University.

Plasma creatinine was analysed using the creatinine-kinetics method (bioMérieux). ${ }^{10}$ The concentration of creatinine was determined in whole plasma by measuring spectrophotometrically the product formed in one minute by the reaction between creatinine and an alkaline picrate solution. Fifty microlitres of whole plasma or standard were added at $25-30^{\circ} \mathrm{C}$ to $500 \mu$ l of reagent (a mixture consisting of $8.8 \mathrm{mmol}$ picric acid and $0.4 \mathrm{~mol}$ $\mathrm{NaOH}$ in equal parts) and the optical density (OD) was read after 20 and 80 seconds at $492 \mathrm{~nm}$. The creatinine concentration was obtained by the following formula: OD plasma/OD standard $\times C$, where $O D=$ difference between the $O D$ at 80 seconds and that at 20 seconds and $\mathrm{C}=$ the concentration of the standard in $\mu \mathrm{mol} / 1$. A recovery study was performed during which $10,50,100$, and $250 \mu \mathrm{l}$ of a $1000 \mu \mathrm{mol} / 1$ creatinine solution were added to $500 \mu \mathrm{l}$ samples of plasma (creatinine concentration $=95 \mu \mathrm{mol} / 1(1.07 \mathrm{mg} / 100 \mathrm{ml}))$ or synthetic plasma standard (creatinine concentration 


\section{Feldman and Guignard}

$=132.2 \mu \mathrm{mol} / 1(1.5 \mathrm{mg} / 100 \mathrm{ml}))$. Creatinine was then determined using the kinetic method. Statistical comparisons between calculated and measured values were made using Student's $t$ test. Results are expressed as mean \pm SEM.

\section{Results}

During the first 5 days of life there was a wide range of creatinine levels; some values were as high as $\mathbf{1 8 8}$ $\mu \mathrm{mol} / \mathrm{l}$, others as low as $17 \mu \mathrm{mol} / \mathrm{l}$ (Fig. 1). Then the levels rapidly diminished and all concentrations were below $62 \mu \mathrm{mol} / 1$ by the time the infants were aged more than five days. The mean plasma creatinine concentration for these 34 infants aged 6-30 days was $35 \pm 2 \mu \mathrm{mol} / \mathrm{l}$ (range 12 to 62 ). Seven of the 22 infants receiving gentamicin had high plasma creatinine levels compared with infants receiving no antibiotic. Several infants more than doubled their plasma creatinine concentration during treatment with drugs (Fig. 2). Creatinine concentrations all declined to premedication values within the first month of life.

Recovery studies showed that the creatinine concentrations measured by the creatinine-kinetics method did not differ significantly from the

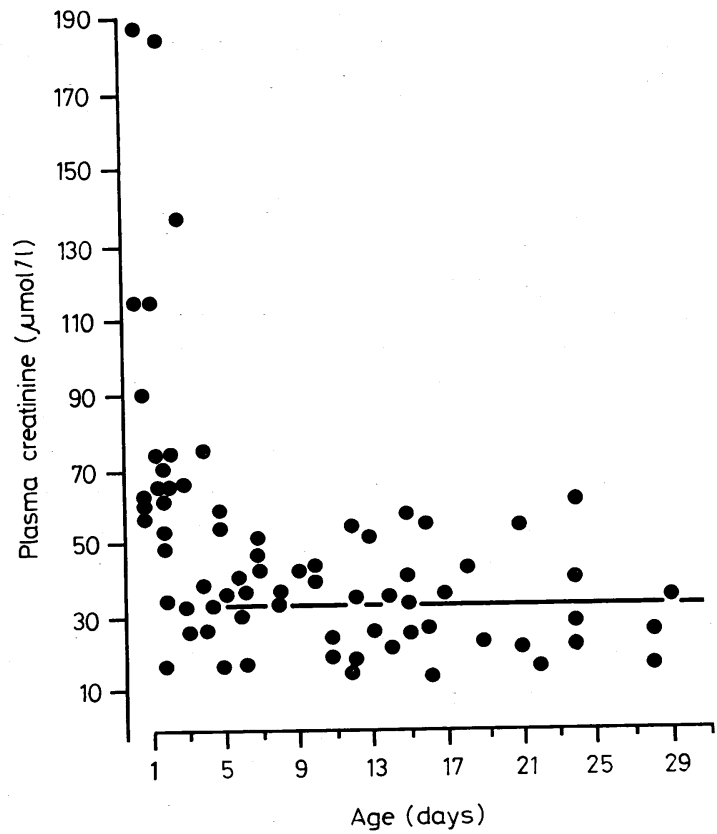

Conversion: SI to traditional units $-1 \mu \mathrm{mol} / 1 \approx 0.0113 \mathrm{mg} / 100 \mathrm{ml}$.

Fig. 1 Plasma creatinine concentrations during the first month of life of 34 neonates receiving no drug therapy.

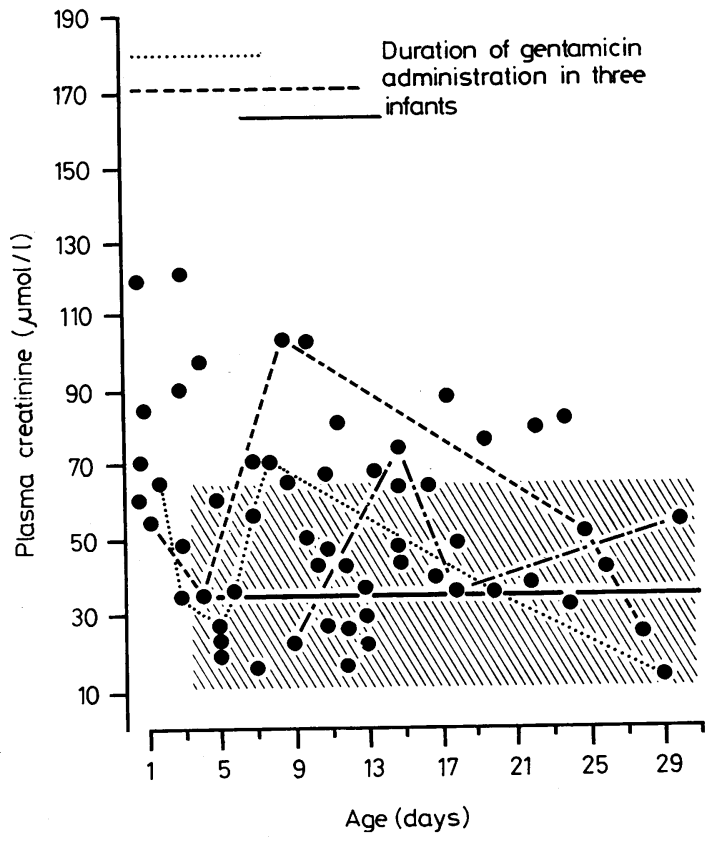

Fig. 2 Plasma creatinine concentrations during the first month of life of 22 neonates treated with gentamicin ampicillin, and cloxacillin. The shaded area shows the range of values observed in control neonates receiving no drugs.

calculated concentrations of our test solutions (mean difference $=2 \cdot 6 \pm 4 \cdot 2 \mu \mathrm{mol} / 1, \mathrm{n}=9, \mathrm{P}>0 \cdot 9)$. The coefficient of variation for the creatinine-kinetics method was calculated to be $5 \cdot 5 \%$ (12 replicates).

\section{Discussion}

The high plasma creatinine concentrations at birth, perhaps maternal in origin, and the decline in levels during the first month of life greatly limit the use of ? creatinine as an index of glomerular filtration in 3 infants. A mean value of plasma creatinine of $1 \cdot 3 \pm 0.07 \mathrm{mg} / 100 \mathrm{ml}(115 \pm 6 \mu \mathrm{mol} / \mathrm{l})$ was noted $\frac{\circ}{3}$ by Stonestreet and $\mathrm{Oh}^{1}$ in infants of low birthweight during the first 10 days of life. Their creatinine values only stabilised at $0.6 \pm 0.05 \mathrm{mg} / 100 \mathrm{ml}$ 응 $(53 \pm 4 \mu \mathrm{mol} / \mathrm{l})$ during the second and third months of life. However, our data show that levels of plasma $N$ creatinine, using the kinetic method, rapidly decline just after birth and stabilise at about $35 \mu \mathrm{mol} / \mathrm{l}$ after the fifth day of life.

A previous study ${ }^{12}$ showed that creatinine values? measured by the kinetic method were consistently ${ }_{C}$ lower than when measured using the autoanalyser $\stackrel{\Phi}{\Phi}$ technique. Values obtained by both methods were ${ }^{?}$ compared in 14 adult volunteers before, and then 3 
and 5 hours after eating a meal containing meat. The mean values of $77 \pm 3,132 \pm 6$, and $95 \pm 6$ $\mu \mathrm{mol} / \mathrm{l}$ measured by the kinetic method were significantly lower than the mean values of $82 \pm 3$, $153 \pm 7$, and $113 \pm 7 \mu \mathrm{mol} / \mathrm{l}$ measured by the autoanalyser. The mean increase in plasma creatinine after eating cooked meat was significantly less when measured by the creatinine-kinetics method ( 55 $\mu \mathrm{mol} / \mathrm{l})$ than by the autoanalyser $(72 \mu \mathrm{mol} / \mathrm{l})$ $(P<0.01)$. This fact, together with the lower creatinine values observed here, suggest that the kinetic method lessens the effect of non-creatinine chromogens. Recovery studies similarly indicate that the lower values that we found using the kinetic method are not explained by an underestimation of creatinine itself. Studies on adults showed that creatinine values measured by the kinetic method were slightly higher than those measured using the Lloyd reagent. These differences however were not statistically significant. The kinetic method permits the Jaffé reaction to proceed only to a point at which probably most of the creatinine, but little of the non-creatinine chromogens have conjugated with alkaline picrate. ${ }^{10} 11$ Furthermore, plasma serves as its own blank thereby increasing the specificity of the analysis and reducing the effect of other yellow pigments-such as bilirubin-that may be present in the blood. We must add a word of caution about interpreting results in severely hyperbilirubinaemic children. Unpublished observations (E Aubert and J-P Guignard, 1981) show that the kinetic method may not be sufficiently sensitive if extreme excesses of bilirubin are present.

Of interest is our finding that 7 out of 22 infants, all of whom received gentamicin, had raised plasma creatinine concentrations during the first month of life. Several infants substantially increased their creatinine concentration during treatment with gentamicin after having had concentrations within the range of values measured in neonates receiving no antibiotics. That these changes could be due to gentamicin toxicity ${ }^{13}$ rather than to their clinical condition is suggested by the decrease of plasma creatinine during the first few days of antibiotic therapy (Fig. 2), when the clinical condition of the infants was probably at its worst. Only after there had been sufficient time for the gentamicin to accumulate in the tissues did the plasma creatinine concentration begin to rise. This observation together with reports of nephrotoxicity seen in adults receiving aminoglycoside antibiotics, ${ }^{14}{ }^{15}$ strongly suggest that the augmentation of plasma creatinine in our patients was a reflection of a transient diminution of renal function. The apparent reversibility of the phenomenon, as demonstrated by the descent of creatinine after the drug had been stopped, and the presence of some infants who were seemingly unaffected by it, are both in keeping with other studies on the nephrotoxicity of gentamicin. ${ }^{131617}$

A rational fluid and drug therapy in the sick neonate with renal insufficiency requires that the level of renal function be accurately estimated in a period of rapid maturational changes. ${ }^{18}$ The kinetic method of creatinine analysis appears to be a valuable tool in this context.

We thank the staff of the neonatal unit, Prof. A Calame, Dr J L Micheli, and Miss V Lennon for advice and help. We are indebted to Mrs E Aubert for developing the kinetic method of creatinine analysis.

This study was supported by the Swiss National Science Foundation, grants Nos 3.917.78 and 3.927.80. H F received a grant from the Fonds Universitaire de Pédiatrie, Lausanne University.

\section{References}

1 Stonestreet B S, Oh W. Plasma creatinine levels in low birthweight infants during the first three months of life. Pediatrics 1978; 61: 788-9.

2 Sertel H, Scopes J. Rates of creatinine clearance in babies less than one week of age. Arch Dis Child 1973; 48: 717-20.

3 Greenhill A, Gruskin A B. Laboratory evaluation of renal function. Pediatr Clin N Am 1976; 23: 661-79.

4 Norman M E, Asadi F K. A prospective study of acute renal failure in the newborn infant. Pediatrics 1979; 63: 475-9.

5 Medani C R, Davitt M K, Huntington D F, Kramer L, Sivasubramanian $K \mathbf{N}$, Jose $P$ A. Acute renal failure in the newborn. In: Pascual J F, Calcagno $P$ L, eds. Nephrologic problems of the newborn. Vol. 15. Basel: Karger, 1979: 47-54.

- Daniel S S, James L S. Abnormal renal function in the newborn infant. $J$ Pediatr 1976; 88: 856-8.

7 Dauber I M, Krauss A N, Symchych P S, Auld P A M. Renal failure following perinatal anoxia. $J$ Pediatr 1976; 88: 851-5.

8 Reimold E W, Don T D, Worthen H G. Renal failure during the first year of life. Pediatrics 1977; 59: 987-94.

9 Guignard J-P, Torrado A, Mazouni S M, Gautier E. Renal function in respiratory distress syndrome. $J$ Pediatr 1976; 88: 845-50.

10 Bartels H, Böhmer M, Heierli C. Serum kreatininbestimmung ohne Enteiweissen. Clin Chim Acta 1972; 37: 193-7.

11 Husdan H, Rapoport A. Estimation of creatinine by the Jaffé reaction: a comparison of three methods. Clin Chem $1968 ; 14: 222-38$.

12 Feldman H, Aubert E, Guignard J-P. Effet d'un repas carné sur la créatinine plasmatique. Rev Med Suisse Romande 1980; 100: 249-55.

13 Szefler S J, Wynn R J, Clarke D F, Buckwald S, Shen D, Schentag J J. Relationship of gentamicin serum concentrations to gestational age in preterm and term neonates. J Pediatr 1980; 97 : 312-5.

14 Smith C R, Maxwell R R, Edwards C Q, Rogers J F, Lietman P S. Nephrotoxicity induced by gentamicin and amikacin. Johns Hopkins Med J 1978; 142: 85-90. 
15 Schentag J J, Cumbo T J, Jusko W J, Plaut M E. Gentamicin tissue accumulation and nephrotoxic reactions. JAMA 1978; 24: 2067-9.

16 Gregory D, Hirschmann J V. Prudent use of the aminoglycosides. Postgrad Med J 1978; 61 : 97-103.

17 Haughey D B, Hilligoss D M, Grassi A, Schentag J J. Two-compartment gentamicin pharmacokinetics in premature neonates: comparison to adults with decreased glomerular filtration rates. J Pediatr 1980; 96: 325-30.
18 Guignard J-P, Torrado A, Da Cunha O, Gautier E. Glomerular filtration rate in the first three weeks of life. J Pediatr 1975; 87: 268-72.

Correspondence to Dr Jean-Pierre Guignard, Service $\overrightarrow{\vec{B}}$ de Pédiatrie, CHUV, 1011 Lausanne, Switzerland.

Received 12 January 1981 